\section{War of the Worlds, 1996}

\author{
Gary K. Meffe
}

In 1938 radio personality Orson Welles panicked a good portion of the eastern United States with his radio adaptation of H. G. Wells's War of the Worlds. Although clearly offered as an entertaining radio play, enough of the listening audience either did not hear, or forgot about, the preliminary announcements that this was merely science-fiction fantasy. Panic ensued when citizens thought the 'news reports' were real, that New Jersey was under massive and hostile attack by Martian spacecraft, leaving widespread death and destruction in its wake. Some people fled the area and, if my memory of the reports is correct, there were even a few suicides. The realism of the play simply overwhelmed many clearthinking people.

In 1996 reliable scientific reports of life on Mars surprised the world and sparked the imaginations of millions. This is no fantasy; life really may exist, or may have existed, on Mars. If it proves to be true, this will rank as one of the great scientific discoveries of all time, with broad implications for the origin of life and our place in the universe. This time, no panic or hostilities are associated with the reports, and scientific rigour and scepticism overrule sensationalism and foolishness. We have made some progress over the last half century. But only some.

For you see, also in 1996, an unknown number of species, probably between several thousand and 10,000, became extinct here on Earth. No excitement, no panic, no fleeing. Not even much news coverage. Just unrecognized and largely unmourned loss, as has occurred each year over the last few decades and as will occur each year for the forseeable future.

That so much excitement is generated about an unproven, primitive life form on Mars is not surprising; it captures the imagination of any cognizant individual. What is surprising, and of greater concern to me, is the simultaneous indifference towards the proven and spectacular diversity of life here on Earth. Whatever life forms may ultimately prove themselves on Mars, surely the amount, complexity and sheer glory of life on Earth will swamp them by many orders of magnitude. So why not the excitement in the lay press about the huge and mostly uncatalogued diversity of life on Earth? More importantly, why is there not unbridled outrage that so much of it is disappearing before our eyes? And why are we not willing to invest the huge resources into Earth's life that will be spent on exploration of the Martian surface?

The Society for Conservation Biology perceptibly noted this misaligned priority immediately after the announcement of the Martian discovery, and at its annual meeting last August discussed concerns about disparities in the study of life. I know of no other discussion about this latest 'Martian invasion' and its comparison with diversity studies on terra firma.

There will be a great push to fund further expeditions to pursue life on Mars, undoubtedly at a cost of hundreds of millions, if not billions, of dollars. Just today, as I write this column, a spacecraft was launched on a 10month journey to the red planet. Yet, while we pursue life on Mars we are failing as a society to come to grips with the fact that life on Earth is little-known and continues to erode and disappear from under us. We do not know, for example, within an order of magnitude, the number of species on Earth. Yet, pitifully little money is going into either cataloguing life here or preventing its extinction; in fact, for lack of funds some museums are being closed or their efforts redirected, and biological collections are endangered. In this age of fiscal conservatism it is worth contemplating how our science dollars are best spent. Can we afford missions in pursuit of life on Mars while life on Earth is in such desperate need of attention? If we could, would we commit to both? Or will Martian missions drain limited science budgets to the extent that the already paltry sums expended on biodiversity are further diminished? Perhaps the larger question is whether we as a people are up to the task of addressing the greatest problem in the history 
of humanity - the loss of the biological world that supports us. Can we in fact mobilize as a unified people to meet this problem head on?

It is possible, but to do so we will need a global push for exploration and preservation of life on Earth at least on par with the massive programmes of the 1960 s to put men on the moon, or of the 1980s and 1990s to explore the universe with the Hubble telescope, build space stations and plan for journeys to Mars. And we need a galvanizing agent with a vision. In 1961 President John Kennedy mobilized the United States for a bold and audacious attempt to put men into space and, in particular, on the moon before 1970, and before the Soviet Union beat the USA to it. He captured our collective imaginations and we all backed the programme. We were glued to our black-and-white television sets as we witnessed humanity's first, tentative steps away from the safe confines of our atmosphere; we thrilled at the first space walk; we mourned the tragic deaths of three American astronauts in a flight-pad fire in 1967; our national pride overflowed as Neil Armstrong announced our peaceful intents from the lunar surface in 1969; and the world shed tears of joy and relief as the men from the badly crippled Apollo 13 emerged from their capsule in the Pacific Ocean. Can we not develop a comparable, global programme to save biological diversity, driven by similar pride, excitement and sense of urgency? Can we find a bold leader who will galvanize such an effort and fire the public imagination? Who will challenge us as we have never been challenged before?

Do not misunderstand me. I am excited about the possibility of life elsewhere in the universe and I think we should investigate it thoroughly. But I believe even more strongly that we should be willing to spend at least as generously to explore and preserve life on Earth, which we know is diverse and which we know is disappearing. By every account, we have catalogued only somewhere between 5 and 20 per cent of Earth's diversity, and we lose perhaps dozens of species per day. This loss will only accelerate as the human population continues to add some 95 million members per year, all of whom strive towards a higher standard of living and consumption of more resources. This problem is known and immediate; the Martian exploration has no urgency to it whatsoever. One hundred years from now, the same evidence will exist in the same forms on Mars; we cannot make this claim for Earth's disappearing diversity.

My fear is that this latest Martian invasion will further deplete limited resources for studies and preservation of biological diversity. The worst-case scenario would take resources from limited science budgets and invest them in Mars. This is truly frightening, much moreso than Welles's antics of nearly 60 years ago. However, this excitement about life on Mars also could be used to re-focus on Earth's life and its problems. My hope is to see the spirit, intensity, pride and generosity that drove our successful space programmes applied to a serious and sustained global biodiversity programme. If we can do this, humanity can reach more lofty goals than any heretofore imagined for the Earth or the heavens.

Gary Meffe is a Professor at the University of Georgia and the Savannah River Ecology Laboratory, and is senior author of Principles of Conservation Biology (Sinauer Associates, 1994). 